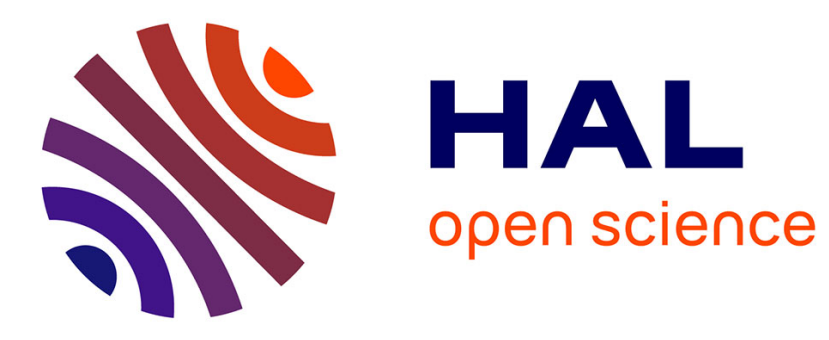

\title{
Phase Noise Measurements of AlN Contour-Mode Resonators
}

Etienne Vaillant, Fabrice Sthal, Joël Imbaud, Valérie Petrini, Philippe Abbé, Lilia Arapan, François Xavier Esnault, Gilles Cibiel, Gianluca Piazza, Jeronimo Segovia-Fernandez

\section{To cite this version:}

Etienne Vaillant, Fabrice Sthal, Joël Imbaud, Valérie Petrini, Philippe Abbé, et al.. Phase Noise Measurements of AlN Contour-Mode Resonators. International Frequency Control Symposium, May 2016, New Orleans, United States. hal-02992059

\section{HAL Id: hal-02992059 \\ https://hal.science/hal-02992059}

Submitted on 6 Nov 2020

HAL is a multi-disciplinary open access archive for the deposit and dissemination of scientific research documents, whether they are published or not. The documents may come from teaching and research institutions in France or abroad, or from public or private research centers.
L'archive ouverte pluridisciplinaire HAL, est destinée au dépôt et à la diffusion de documents scientifiques de niveau recherche, publiés ou non, émanant des établissements d'enseignement et de recherche français ou étrangers, des laboratoires publics ou privés. 


\section{Phase Noise Measurements of AlN Contour-Mode Resonators}

Etienne Vaillant, Fabrice Sthal, Joël Imbaud, Valérie Petrini, Philippe Abbe, Lilia Arapan,

F. X. Esnault", G. Cibiel* FEMTO-ST Institute

UFC, CNRS, ENSMM, UTBM, UBFC

Besançon, France

${ }^{*}$ CNES, Toulouse, France

fsthal@ens2m.fr

\begin{abstract}
In this paper, passive measurement system is used to explore the phase noise of aluminum nitride contour mode resonators. Their resonant frequencies are around $220 \mathrm{MHz}$. The carrier suppression technique is used. The noise floor of the measurement system is around $-135 \mathrm{dBc} / \mathrm{Hz} @ 1 \mathrm{~Hz}$ offset from the carrier. Then, measurements of several resonators are presented and discussed.
\end{abstract}

Keywords-1/f noise; resonator; AlN; contour-mode resonators; microelectromechanical systems (MEMS) resonators; phase noise; carrier suppression technique.

\section{INTRODUCTION}

Many laboratories develop currently resonators dedicated to time bases by means of collective process and using microtechnologies [1-6]. Some of the oscillators produced by these MEMS technologies could be perturbed by the inherent noise of the resonator which limits performances. The Carnegie Mellon University in Pittsburgh made the choice of technologies in AlN piezoelectric thin film using contour vibrating modes that are compatible with CMOS integration technologies [7]. In this paper, we propose to measure the inherent noise of these acoustic resonators without the associated oscillator. The main principle of these set-ups is the carrier suppression method. The resonant frequency of this type of resonator is set by the width of the finger and the acoustic velocity of the resonator stack. Characterization of $220 \mathrm{MHz}$ aluminum nitride contour-mode resonators (CMR) is given and discussed (Fig. 1).

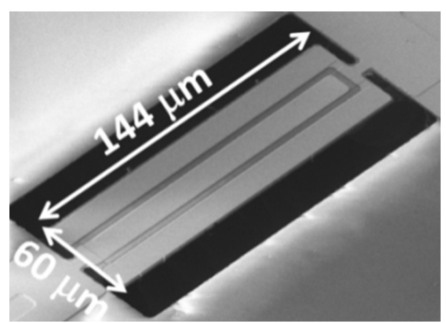

Fig. 1. Scanning electron micrograph of typical $220 \mathrm{MHz}$ AlN contour-mode resonator fabricated at CMU and characterized in this study.

A set of four AlN CMRs have been tested and measured. First, the intrinsic parameters of these resonators are presented.

\author{
Gianluca Piazza, Jeronimo Segovia-Fernandez \\ Department of Electrical and Computer Engineering \\ Carnegie Mellon University \\ Pittsburgh, Pennsylvania, USA, 15213 \\ Email: piazza@ece.cmu.edu
}

Then the transfer function of the packaged devices is shown in order to evaluate their loaded quality factor. Finally, results of phase noise measurement are summarized.

\section{RESONATORS CHARACTERISTICS}

The electrical model to describe the resonance response of AlN CMRs is given in Fig. 2. It is the usual model of a quartz crystal resonator.

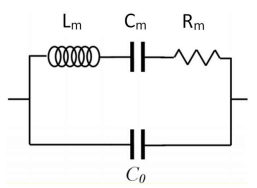

Fig. 2. Electrical model of an AIN CMR resonator whose motional parameters are $L_{m}, R_{m}, C_{m}$ and $C_{0}$.

Impedance response has been measured for a set of four resonators in order to evaluate their intrinsic quality factors. Impedance plots are shown in Fig. 3. Each letter $G, I, L$ and $N$ corresponds to a different resonator.
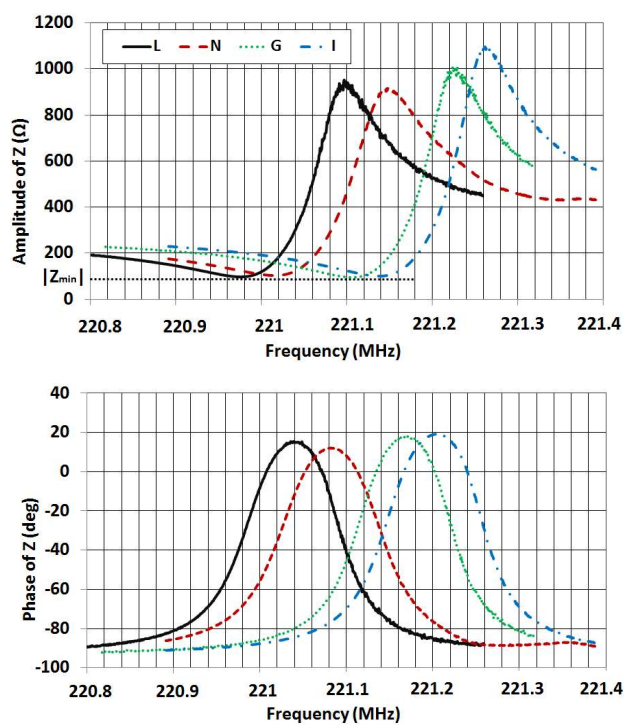

Fig. 3. Tested impedance response $\mathrm{Z}$ (amplitude (top) and phase) of four AIN CMR resonators. 
Motional parameters of these resonators are given in Table I.

TABLE I. MOTIONAL PARAMETERS OF THE ALN CONTOUR-MODE RESONATORS

\begin{tabular}{|c|c|c|c|c|c|c|}
\hline Res. & $\boldsymbol{R}_{\boldsymbol{m}}(\boldsymbol{\Omega})$ & $\begin{array}{c}\boldsymbol{L}_{\boldsymbol{m}} \\
(\boldsymbol{m H})\end{array}$ & $\begin{array}{c}\boldsymbol{C}_{\boldsymbol{m}} \\
(\boldsymbol{f F})\end{array}$ & $\begin{array}{c}\boldsymbol{C}_{\boldsymbol{o}} \\
(\boldsymbol{p F})\end{array}$ & $\boldsymbol{Q}$ & $\begin{array}{c}\boldsymbol{f}_{\text {res.(Zmin) }} \\
(\boldsymbol{M H z})\end{array}$ \\
\hline $\boldsymbol{I}$ & 110 & 0.269 & 1.93 & 2.14 & 3398 & 221.140 \\
\hline $\boldsymbol{L}$ & 109 & 0.258 & 2.01 & 2.37 & 3286 & 220.980 \\
\hline $\boldsymbol{G}$ & 106 & 0.264 & 1.96 & 2.30 & 3473 & 221.100 \\
\hline $\boldsymbol{N}$ & 116 & 0.257 & 2.02 & 2.26 & 3077 & 221.020 \\
\hline
\end{tabular}

The motional parameters are computed by the impedance analyzer (4395A) according the equivalent circuit (Fig. 2). The motional resistance is about $100 \Omega$. The $\mathrm{Q}$ factors have been calculated using the equation (1) and are around 3000 which fits with previous publication [7].

$$
Q=\frac{2 \pi \cdot f_{\text {res }} \cdot L_{m}}{R_{m}}
$$

\section{CONDITIONING OF RESONATORS}

To reduce the impact of thermal fluctuations, the chip containing the four resonators was glued into a TO8 package. The four resonators have been bonded in separate pins. The TO8 package is then inserted into an oven. The temperature was fixed around $55^{\circ} \mathrm{C}$. The purpose of this setup was not to get the turnover point, but to avoid environmental temperature fluctuations. A picture of the oven is shown in Fig. 4.

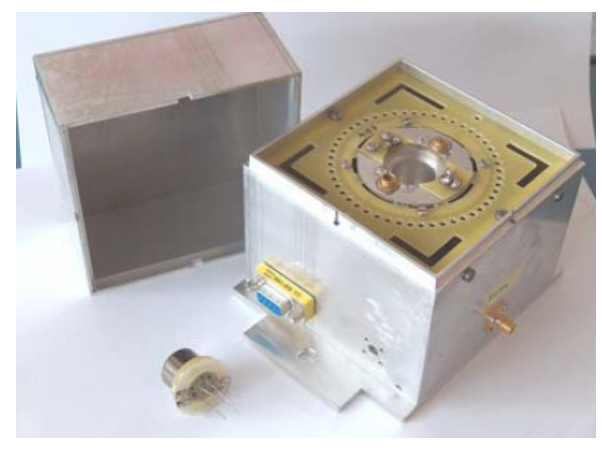

Fig. 4. Oven used to stabilize the external temperature around $55^{\circ} \mathrm{C}$.

The motional resistor of all the tested AlN CMRs is around $100 \Omega$. As the oven's impedance is adapted upstream and downstream, it is important to adjust this adaptation at the input of the Device Under Test (DUT) inside the oven, as shown in Fig. 5.

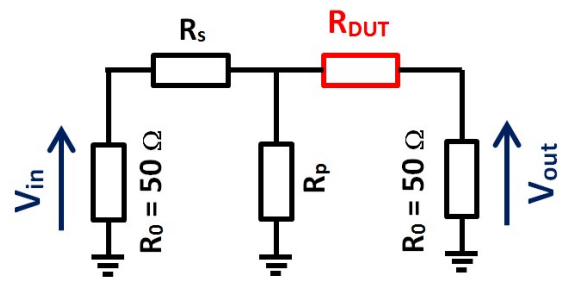

Fig. 5. Impedance matching for resonators.
$R_{s}$ and $R_{p}$ are around $30 \Omega$ and $20 \Omega$ respectively. The loaded quality factor has been calculated from the transfer function obtained with the Network Analyzer. This measurement has been done between the input and output of the oven. Consequently every component and cable inside the oven took part in the measurement. At the resonant frequency the loss induced by the resonators is around $15 \mathrm{~dB}$ and the loaded quality factor has been estimated around 1200 for the four tested resonators (details in Table II). This resonator setup is used for the noise measurement and the loaded Q values are used to estimate the flicker floor in term of Allan standard deviation [8].

The Leeson frequency $F_{L}$ can be defined according to (2):

$$
F_{L}=\frac{1}{\frac{\Delta \emptyset}{\Delta f}}
$$

where $\frac{\Delta \emptyset}{\Delta f}$ is the slope of the phase at the resonant frequency of the resonator, converted in $\mathrm{rad} / \mathrm{Hz}$. The $\mathrm{Q}$ factor is then calculated using the following expression:

$$
Q_{L}=\frac{f_{r e s}}{2 \cdot F_{L}}
$$

TABLE II. LOADED Q FACTOR AND LOSS AT RESONANCE OF THE RESONATORS

\begin{tabular}{|c|c|c|c|c|}
\hline Res. & $\boldsymbol{I}$ & $\boldsymbol{L}$ & $\boldsymbol{G}$ & $\boldsymbol{N}$ \\
\hline Loss (dB) & 15.4 & 15.2 & 15 & 15.5 \\
\hline $\begin{array}{c}\text { Phase slope } \\
\left(\mathbf{1 0}^{-6} \mathbf{r a d} / \boldsymbol{H z}\right)\end{array}$ & 9.68 & 10.3 & 11.4 & 10.6 \\
\hline $\boldsymbol{F}_{\boldsymbol{L}}(\boldsymbol{H z})$ & 103200 & 97087 & 87719 & 94340 \\
\hline $\boldsymbol{Q}_{\boldsymbol{L}}$ & 1071 & 1138 & 1260 & 1171 \\
\hline
\end{tabular}

\section{MEASUREMENT SYSTEM}

The passive technique using carrier suppression is used to characterize the inherent phase stability of the resonators [8]. The principle of the carrier suppression bench is shown in Fig. 6. The general idea of this passive method consists in reducing the noise of the source as much as possible. This suppression is obtained by a first stage where signals of both ways are subtracted and then the resulting signal is amplified. More precisely a part of the source signal is separated in two equal parts in order to drive the DUT. The DUT can be either a resistor allowing the calibration of the system so as to establish its resolution, or a resonator whose phase noise is sought. The attenuation of the DUT is compensated by an attenuator in the second arm. After that the two signals are vectorially added with a $180^{\circ}$ phase shift. The carrier suppression is done with a power splitter $\left(0^{\circ}\right.$ to $\left.180^{\circ}\right)$ before the classical phase detection. Obtaining high carrier suppression requires a fine adjustment of both amplitude and phase of the two signals.

The resulting signal is highly amplified without saturation of the amplifier (of gain $\beta$ ). This signal is then subjected to the phase detection mixing with the input signal in phase quadrature and then amplified (gain $\beta^{\prime}$ ) to be higher than the noise floor of the Fast Fourier (FFT) spectrum analyzer. 


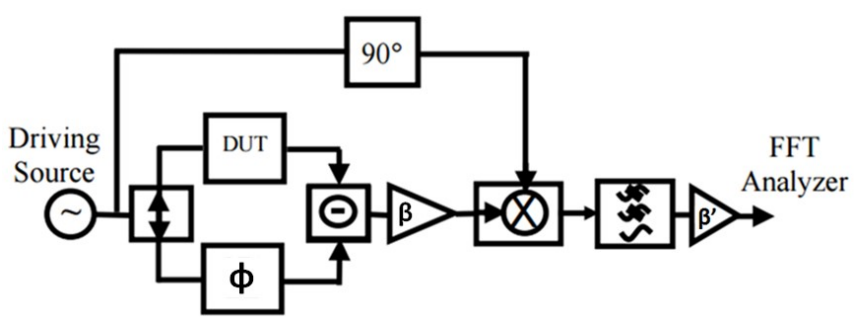

Fig. 6. Principle of the carrier suppression technique.

A picture of our implementation is shown in Fig. 7. Calibration of the measurement system is obtained by injecting a known sideband on one of the arms of the bridge. This sideband simulates an equivalent phase noise. The result of the measurement is corrected using the calibration factor determined from this sideband.

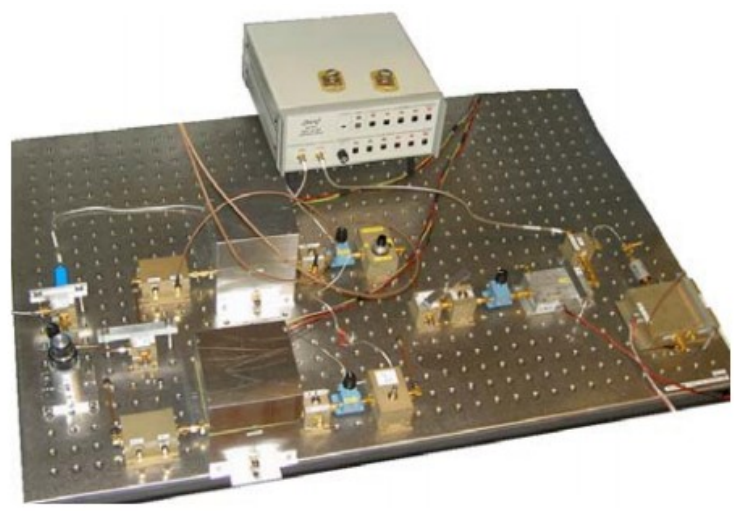

Fig. 7. Carrier Suppression technique setup.

The noise floor of the system is presented at $221 \mathrm{MHz}$ in Fig. 8. The system exhibits a $\mathcal{L}(1 \mathrm{~Hz})$ around $-136 \mathrm{dBc} / \mathrm{Hz}$, $\mathcal{L}(10 \mathrm{~Hz})=-148 \mathrm{dBc} / \mathrm{Hz}$ and then a thermal floor near -154 $\mathrm{dBc} / \mathrm{Hz}$. For this noise floor measurement a resistor has been used instead of a resonator. The dissipated power by the resistor is about $140 \mu \mathrm{W}$.

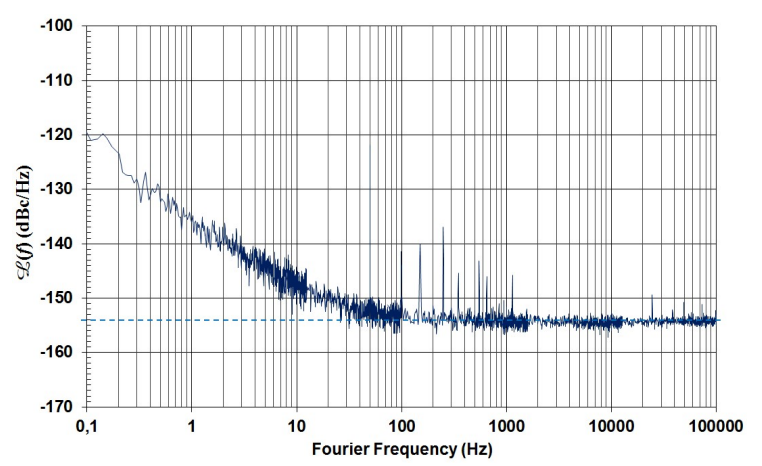

Fig. 8. Noise floor of the measuremnt system at $221 \mathrm{MHz}$.

The driving source was coming from a $1 \mathrm{GHz}$ Cryogenic Sapphire Oscillator (CSO) signal divided by a Direct Digital Synthesizer (DDS, AD9912). The advantage of a DDS is the possibility to adjust the frequency with a very high resolution in order to get the resonant frequencies of the resonators.

\section{PRELIMINARY RESULTS}

A measured example of the single sideband Power Spectral Density (PSD) of phase fluctuation, $\mathcal{L}(f)$, is presented in Fig. 9. The drive level power dissipated by the resonator is about $140 \mu \mathrm{W}$. The noise of the resonator is at least $10 \mathrm{~dB}$ above the noise floor of the system, as measured by using a resistor instead of the resonator. We can observe the $1 / f$ noise of the resonator. In this case, the loaded Q is about 1200 , then, the cut-off frequency $F_{L}$ is close to $90 \mathrm{kHz}$. Thus the filter part in $1 / f^{3}$ slope is not visible and it is hidden by the noise floor of the measurement system.

The best resonator shows a phase noise of $-125 \mathrm{dBc} / \mathrm{Hz}$ at $1 \mathrm{~Hz}$ offset from the carrier. A summary of the phase noise measurement results for the four AIN devices is given in Table III. The resonators have been measured with different driving powers: 35,70 and $140 \mu \mathrm{W}$. In this kind of measurement the error in the determination of $\mathcal{L}(f)$ is usually $\pm 2 \mathrm{~dB}$ because of the FFT analyzer precision. The measured noise given by the passive measurement can be transformed into equivalent oscillator noise $\left(b_{-3}^{\prime}\left(\mathrm{dBrad}^{2} / \mathrm{Hz}\right)\right)$ and into Allan standard deviation $\left(\sigma_{y_{-} \text {floor }}\left(10^{-9}\right)\right)[9]$.

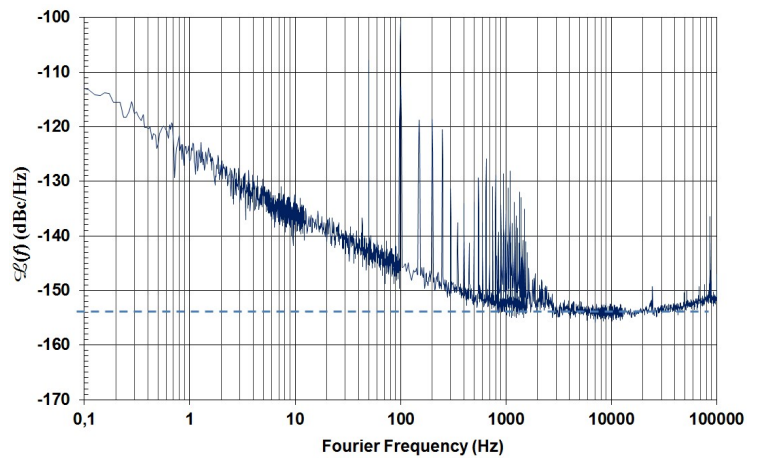

Fig. 9. Power spectral density of the phase fluctuations of a AlN contour mode resontaor, dissipated power is around $140 \mu \mathrm{W}$.

TABLE III. NOISE RESULTS OF SEVERAL ALN CMRS FOR THREE DIFFERENT DISSIPATED POWERS

\begin{tabular}{|c|c|c|c|c|}
\hline Power & \multicolumn{4}{|c|}{$35 \mu W$} \\
\hline Res. & $I$ & $L$ & $G$ & $N$ \\
\hline$Q_{L}$ & 1071 & 1138 & 1260 & 1171 \\
\hline $\mathscr{L}(1 \mathrm{~Hz}) \mathrm{dBc} / \mathrm{Hz}$ & -125 & -115 & -118 & -117 \\
\hline$S_{\varphi}(1 \mathrm{~Hz})\left(\mathrm{dBrad}^{2} / \mathrm{Hz}\right)$ & -122 & -112 & -115 & -114 \\
\hline$b_{-3}^{\prime}\left(\mathrm{dBrad}^{2} / \mathrm{Hz}\right)$ & -21.7 & -12.3 & -16.2 & -14.6 \\
\hline$\sigma_{y}$ floor $\left(10^{-9}\right)$ & 0.44 & 1.30 & 0.83 & 0.99 \\
\hline
\end{tabular}

\begin{tabular}{|c|c|c|c|c|}
\hline Power & \multicolumn{4}{|c|}{$70 \mu W$} \\
\hline Res. & $I$ & $L$ & $G$ & $N$ \\
\hline$Q_{L}$ & 1071 & 1138 & 1260 & 1171 \\
\hline $\mathscr{L}(1 \mathrm{~Hz}) \mathrm{dBc} / \mathrm{Hz}$ & -120 & -117 & -115 & -113 \\
\hline$S_{\varphi}(1 \mathrm{~Hz})\left(\mathrm{dBrad}^{2} / \mathrm{Hz}\right)$ & -117 & -114 & -112 & -110 \\
\hline$b_{-3}^{\prime}\left(\mathrm{dBrad}^{2} / \mathrm{Hz}\right)$ & -16.7 & -14.3 & -13.2 & -9.6 \\
\hline$\sigma_{y}$ floor $\left(10^{-9}\right)$ & 0.77 & 1.03 & 1.17 & 1.76 \\
\hline
\end{tabular}

\begin{tabular}{|c|c|c|c|c|}
\hline Power & \multicolumn{4}{|c|}{$140 \mu W$} \\
\hline Res. & $I$ & $L$ & $G$ & $N$ \\
\hline$Q_{L}$ & 1071 & 1138 & 1260 & 1171 \\
\hline $\mathscr{L}(1 \mathrm{~Hz}) \mathrm{dBc} / \mathrm{Hz}$ & -125 & -113 & -112 & -113 \\
\hline$S_{\varphi}(1 \mathrm{~Hz})\left(\mathrm{dBrad}^{2} / \mathrm{Hz}\right)$ & -122 & -110 & -109 & -110 \\
\hline$b_{-3}^{\prime}\left(\mathrm{dBrad}^{2} / \mathrm{Hz}\right)$ & -21.7 & -13.3 & -10.2 & -9.6 \\
\hline$\sigma_{y}$ floor $\left(10^{-9}\right)$ & 0.44 & 1.15 & 1.65 & 1.76 \\
\hline
\end{tabular}


One of the tested resonators exhibits a flicker floor of about $10^{-10}$. The others are more close to $10^{-9}$. In this set of experiment the driving power dependence of the resonator noise is not clearly shown. Further investigation will be necessary to conclude about this last point. Another perspective of this work is to measure several other AlN resonators and to use them in an oscillator circuit.

\section{CONCLUSION}

Phase noise of Aluminum Nitride Contour Mode Resonators has been explored using a passive measurement system with carrier suppression. The $1 / f$ noise of acoustic resonators is clearly shown. These resonators present a good short-term stability around few $10^{-9}-10^{-10}$ which is in the same order of magnitude than usual TCXO.

\section{ACKNOWLEDGMENT}

Authors thank the "Région Franche-Comté", the OscillatorIMP project (PIA ANR) and CNES for the founding support and the other members of the discussion group of "MEMS Noise" for their helpful discussions (T. Baron, B. Dulmet, V. Giordano, S. Galliou, G. Martin and E. Rubiola).

\section{REFERENCES}

[1] T. L. Naing, T. O. Rocheleau, E. Alon, C. Nguyen, A "78- $\mu$ W GSM Phase Noise-Compliant Pierce Oscillator Referenced to a $61-\mathrm{MHz}$ Wine-Glass Disk Resonator", in Proc. IEEE Int. Freq. Contr. Symp., pp. 562-565, 2013.
[2] G. Piazza, A. Tazzoli, N. Miller, J. Segovia, C. Cassella, J. Koo, B. Otis, K. McNaul, B. Gibson, K. Turner, T. Palmer, "Dynamics of Microscale Thin Film AlN Piezoelectric Resonators Enables Low Phase Noise UHF Frequency Sources", in Proc. IEEE Int. Freq. Contr. Symp., pp. 555558,2013

[3] R.G. Nagele, H.P. Moyer, D. J. Kirby, Y. Yoon, R. L. Kubena, R. J. Joyce, P. D. Brewer, D. T. Chang, "A 995 MHz Fundamental Nonlinear Quartz MEMS Oscillator”, in Proc. IEEE Int. Freq. Contr. Symp., pp. 566-570, 2013

[4] M.E. Ivan, B. Dulmet, G. Martin, P. Abbe, L. Robert, S. Ballandras, "New electrostatically-excited single crystal silicon resonator vibrating in a Thickness-Extensional mode", in Proc. IEEE Int. Freq. Contr. Symp., pp. 743-748, 2012.

[5] T. Barron, D. Gachon, G. Martin, S. Alzuaga, D. Hermelin, J.P Romand, S. Ballandras, "Temperature Compensated Radio-Frequency Harmonic Bulk Acoustic Resonators", in Proc. IEEE Int. Freq. Contr. Symp., pp. 652-655, 2012.

[6] P. Varshney, B. S. Panwar, P. Rathore, S. Balandras, B. François, G. Martin, J. M. Friedt, T. Retornaz, "Theoretical and experimental analysis of high Q SAW resonator transient response in a wireless sensor interrogation application", in Proc. IEEE Int. Freq. Contr. Symp., pp. 451-456, 2012.

[7] N. Miller, G. Piazza, "Measurements of Frequency Fluctuations in Aluminum Nitride Contour-Mode Resonators", IEEE Transactions on Ultrasonics, Ferroelectrics and Frequency Control, vol. 61, no. 6, June, pp. 913-919, 2014

[8] F. Sthal J. Imbaud, X. Vacheret, P. Salzenstein, G. Cibiel, S. Galliou, "Computation Method for the Short-Term Stability of Quartz Crystal Resonators Obtained From Passive Phase Noise Measures", IEEE Transactions on Ultrasonics, Ferroelectrics and Frequency Control, vol. 60, no. 7, July, pp. 1530-1532, 2013.

[9] E. Rubiola, "Phase noise and frequency stability in oscillators", Cambridge University Press, 2009. 